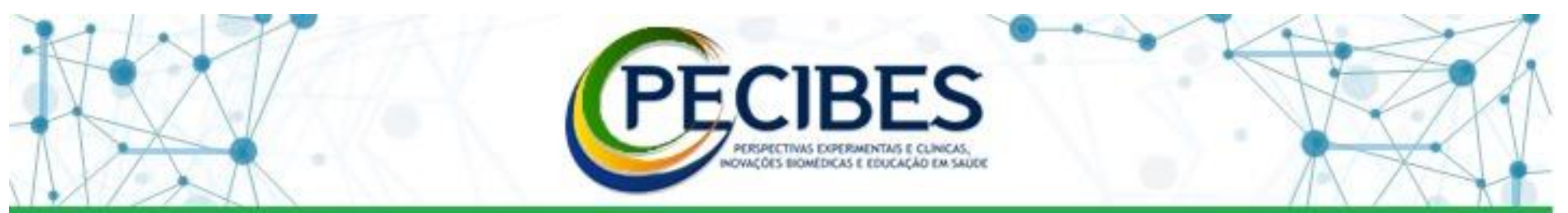

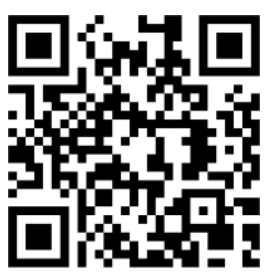

http://www.seer.ufms.br/in dex.php/pecibes/index

* Autor correspondente: Daniela Miyuki Sato, Universidade Federal de Mato Grosso do SulUFMS.E-mail: danymih@hotmail.com

Descritores: Diabetes mellitus. Autocuidado. Consulta de

Enfermagem. Sistema

Único de Saúde.

Integralidade em Saúde.

Key-words: Diabetes mellitus. Self care.

Nursing consultation. Unified Health System. Integrality in Health.

Descriptores: Diabetes mellitus. Autocuidado.

Consulta de enfermaría. Sistema Único de Salud. Integralidad en Salud.

\section{Complicações por Diabetes Melittus Tipo 2 e o manejo na Atenção Primária à Saúde: relato de experiência}

Type 2 Diabetes Melittus Complications and Management in Primary Health Care: an experience report

Daniela Miyuki Sato ${ }^{1}$, Elen Ferraz Teston ${ }^{2}$, Sara Ingrid de Rezende Ferreira ${ }^{3}$, Juliete Bispo dos Santos Mandu ${ }^{4}$

1. Graduanda em Enfermagem. Universidade Federal de Mato Grosso do Sul. Campo Grande, Mato Grosso do Sul, Brasil.

2. Enfermeira. Doutora. Departamento de Enfermagem da Universidade Federal de Mato Grosso do Sul.Campo Grande, Mato Grosso do Sul, Brasil.

3. Enfermeira. Residência Multiprofissional em Saúde da Família, Faculdade Pequeno Príncipe, Secretaria Municipal de Saúde. Curitiba, Paraná, Brasil.

4. Enfermeira. Universidade Federal de Mato Grosso do Sul. Campo Grande, Mato Grosso do Sul, Brasil.

Introdução: o Diabetes Mellitus tipo 2 (DM2) é importante causa de morbimortalidade devido aos desfechos nocivos das alterações metabólicas do organismo. Essa condição multifatorial e progressiva pode levar a complicações e perdas funcionais, o que exige cuidados permanentes com destaque às ações individuais e sistematizadas executadas na consulta de enfermagem. Objetivo: relatar a experiência de uma intervenção em saúde ancorada aos preceitos do Autocuidado Apoiado. Material e métodos: relato de experiência de intervenção em saúde realizada a usuário com complicações de DM2 e estratificado em Risco Alto, cadastrado em uma equipe de Estratégia Saúde da Família de uma capital da região centro-oeste brasileira. A intervenção no domicílio constituiu-se de seis encontros que foram distribuidos de forma semanal e seguiu um cronograma de execução e emprego das seguintes ferramentas: Diagrama de Ishikawa, Genograma, Ecomapa e implementação do Autocuidado Apoiado (AA). No primeiro encontro foi realizada anamnese, exame físico, avaliações do pé diabético e histórico de exames laboratoriais, e reavaliação da estratificação de risco. Ao segundo, junto ao médico, solicitação de novos exames, ajustes de receita, orientação do curso da doença e da importância na pactuação de metas para apoiar a mudança de comportamento e o autocuidado. Por sua vez, no terceiro e quarto encontro ocorreu a construção e implementação dos planos de cuidado com enfoque na adesão à insulinoterapia, metas para favorecer a reeducação alimentar e controle glicêmico e cuidados com pé diabético. Ocorreu a avaliação das intervenções por meio do cumprimento das ações do plano pelo usuário e seu encaminhamento ao nutricionista e psicólogo. Resultados: a intervenção permitiu ao indivíduo refletir sobre o processo saúde-doença e possibilitou melhora nos valores glicêmicos e na cicatrização da ferida. Conclusões: ações de intervenção com base no AA possibilitam melhores resultados de saúde, dado que o usuário torna-se responsável por gerir seu processo terapêutico. 